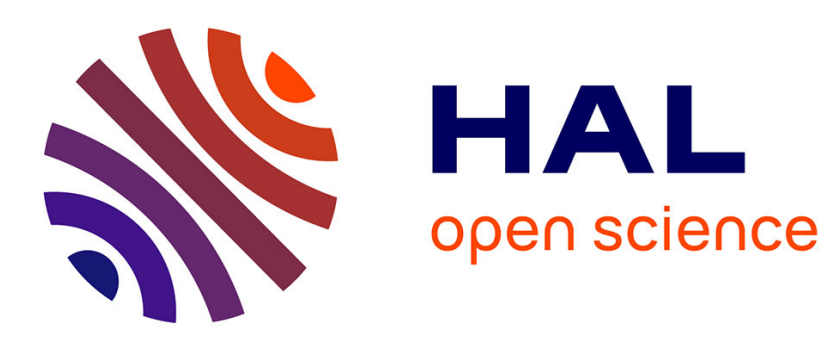

\title{
A High-Tc Superconductor Bolometer for Remote Sensing of Atmospheric $\mathrm{OH}$
}

M. de Nivelle, M. Bruijn, M. Frericks, R. de Vries, J. Wijnbergen, P. de Korte, S. Sánchez, M. Elwenspoek, T. Heidenblut, B. Schwierzi, et al.

\section{- To cite this version:}

M. de Nivelle, M. Bruijn, M. Frericks, R. de Vries, J. Wijnbergen, et al.. A High-Tc Superconductor Bolometer for Remote Sensing of Atmospheric OH. Journal de Physique IV Proceedings, 1996, 06 (C3), pp.C3-423-C3-428. 10.1051/jp4:1996364 . jpa-00254282

\section{HAL Id: jpa-00254282 https://hal.science/jpa-00254282}

Submitted on 1 Jan 1996

HAL is a multi-disciplinary open access archive for the deposit and dissemination of scientific research documents, whether they are published or not. The documents may come from teaching and research institutions in France or abroad, or from public or private research centers.
L'archive ouverte pluridisciplinaire HAL, est destinée au dépôt et à la diffusion de documents scientifiques de niveau recherche, publiés ou non, émanant des établissements d'enseignement et de recherche français ou étrangers, des laboratoires publics ou privés. 


\title{
A High- $T_{c}$ Superconductor Bolometer for Remote Sensing of Atmospheric OH
}

M.J.M.E. de Nivelle, M.P. Bruijn, M. Frericks, R. de Vries, J.J. Wijnbergen, P.A.J. de Korte, S. Sánchez*, M. Elwenspoek*, T. Heidenblut**, B. Schwierzi**, W. Michalke*** and E. Steinbeiss***

Space Research Organization Netherlands, Sorbonnelaan 2, 3584 CA Utrecht, The Netherlands

* MESA Research Institute, P.O. Box 217, 7500 AE Enschede, The Netherlands

** Institut für Halbleitertechnologie und Werkstoffe der Electrotechnik, Universität Hannover, 30167 Hannover, Germany

*** Institut für Physikalische Hochtechnologie, Helmholtzweg 4, 07743 Jena, Germany

\begin{abstract}
The technological feasibility is being investigated of a high- $T_{c}$ superconductor transition edge bolometer for far-infrared detection, which can meet the requirements of a Fabry-Perot based satellite instrument designed for remote sensing of atmospheric $\mathrm{OH}$. These include a time constant $\tau<0.3 \mathrm{~s}$, an operating temperature above $35 \mathrm{~K}$, a diameter of $1.1 \mathrm{~mm}$, and a noise equivalent power (NEP) smaller than about $4.0^{\cdot 10^{-12}} \mathrm{~W} \mathrm{~Hz}^{-1 / 2}$ for radiation with $\lambda \approx 85$ $\mu \mathrm{m}$. Presently, no other sensor can meet these requirements.

A NEP value of $3 \cdot 10^{-11} \mathrm{~W} / \mathrm{Hz}^{1 / 2}$ and $\tau \approx 0.4 \mathrm{~ms}$ has been realized with high- $\mathrm{T}_{\mathrm{c}}$ bolometers on Si membranes with a receiving area of $0.85 \times 0.85 \mathrm{~mm}^{2}$. By replacing the $\mathrm{Si}$ by $\mathrm{Si}_{3} \mathrm{~N}_{4}$ we expect that the thermal conductance $\mathrm{G}$ can be reduced by more than a factor 20 . This should result in a NEP less than $4 \cdot 10^{-12} \mathrm{~W} / \mathrm{Hz}^{-1 / 2}$ and a time constant $<0.1 \mathrm{~s}$.

A bond-and-etch-back technique is used to prepare a mono crystalline silicon top layer on the $\mathrm{Si}_{3} \mathrm{~N}_{4}$ membrane, which is necessary for the epitaxial growth of the superconductor. An absorption layer will be added to the detector to enhance the efficiency. Promising candidates for use as an absorption layer are metal black films with an efficiency $\eta$ around $80 \%$ at $85 \mu \mathrm{m}$ wavelength.
\end{abstract}

\section{INTRODUCTION}

In the context of the PIRAMHYD program (Passive Infra-Red Atmospheric Measurements of HYDdroxyl) of the European Space Agency (ESA) we are investigating the fabrication of a high- $\mathrm{T}_{c}$ superconductor transition edge bolometer.

The PIRAMHYD program aims at the global monitoring of important species in the atmospheric chemistry by limb sounding of self-emitted radiation. Hydroxyl has the first priority because of its central importance in stratospheric chemistry and the lack of data on its concentration. A few different measurement techniques are being investigated, i.e. a Fourier transform spectrometer, a heterodyne receiver and the $\mathrm{OH}$ Interferometer Observations (OHIO) instrument.

The OHIO instrument includes a Fabry-Perot and reflection grating for selection of the $84.42 \mu \mathrm{m}$ emission line of $\mathrm{OH}[1]$. The observation time, the $\mathrm{OH}$ line intensity, the throughput and transmission of the Fabry-Perot and the necessary Signal-to-Noise ratio dictate the detector requirements: i.e. a diameter of $1.1 \mathrm{~mm}$, a time constant less than $0.3 \mathrm{~s}$ and a Noise Equivalent Power (NEP) better than $4.0 \cdot 10^{-12}$ $\mathrm{W} / \sqrt{\mathrm{Hz}}$. To increase operation time the instrument is designed for cooling by a mechanical cryocooler. This requires an operational temperature of the detector larger than $35 \mathrm{~K}$.

For wavelengths $<20 \mu \mathrm{m}$ liquid nitrogen cooled photodetectors like $\mathrm{HgCdTe}$ can be used, but for longer wavelengths and temperatures above $35 \mathrm{~K}$ none of the presently available detectors can meet the requirements. Most promising are bolometers with a high- $\mathrm{T}_{\mathrm{c}}$ superconductor transition edge thermometer [2] .

Recently we reported on high $-\mathrm{T}_{\mathrm{c}} \mathrm{GdBa}_{2} \mathrm{Cu}_{3} \mathrm{O}_{7-8}$ transition edge bolometers on micromachined silicon membranes with an operating temperature of about $85 \mathrm{~K}$ [3]. For the fabrication an epitaxial $\mathrm{YSZ}+\mathrm{CeO}_{2}$ buffer layer and an inhibition patterning technique were used. However, due to the high thermal conductance of the silicon membrane, the sensitivity is too small for the OHIO instrument. A calculation of the 
thermal conduction noise shows that the NEP requirement imposes an upper limit on the thermal conductance $\mathrm{G}$ of about $3 \cdot 10^{-5} \mathrm{~W} / \mathrm{K}$. In order to realize this value we aim at the replacement of the silicon by silicon nitride which has a much smaller thermal conductivity.

At $85 \mu \mathrm{m}$ wavelength the reflectivity of $\mathrm{GdBa}_{2} \mathrm{Cu}_{3} \mathrm{O}_{7-8}$ is almost $100 \%$. To improve the efficiency in the far infrared an absorption layer will be added to the design. We will investigate different options like gold- or silver blacks and thin resistive metallic layers.

In this presentation we discuss the preparation technology, the first results and the expected performance of the $\mathrm{Si}_{3} \mathrm{~N}_{4}$ membrane bolometers.

\section{PREPARATION TECHNOLOGY}

Analysis of available data on the $1 /$ f-voltage noise of high- $T_{c}$ films shows that its contribution to the NEP of the detector remains within the requirements, provided that the superconducting film is of good epitaxial quality [4]. To enable epitaxial growth of the superconductor, a single crystalline $\mathrm{Si}$ layer is required on top of the $\mathrm{Si}_{3} \mathrm{~N}_{4}$ membrane. A cross section of the obtained multilayer structure is shown in Fig. 1. Here we will focus on the preparation of the $\mathrm{Si}_{3} \mathrm{~N}_{4}$ membranes with a single crystalline Si top layer, which is a technological key issue in the production process. For the deposition of the $\mathrm{YSZ} / \mathrm{CeO}_{2}$ bufferlayer, the preparation of the inhibition pattern, the growth of the high- $\mathrm{T}_{c}$ superconductor, the deposition of the $\mathrm{PtO}_{\mathrm{x}}$ passivation layer and the laser writing of the Pt contacts, we refer to [3].
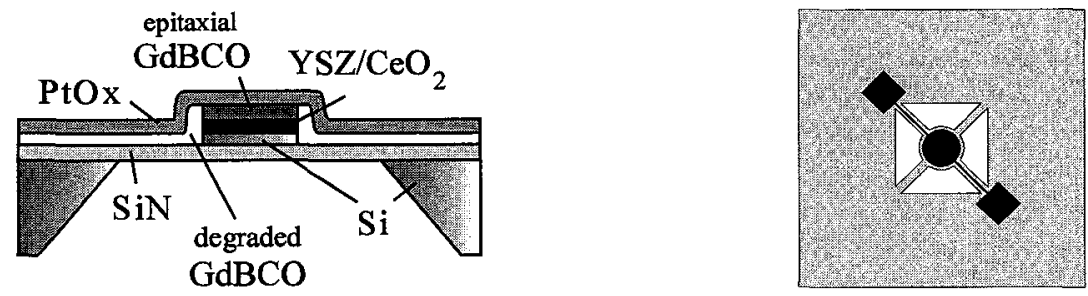

Figure 1: Cross section and top view and of the high-Tc bolometer

\subsection{Bond-And-Etch-Back Technologies}

For the production of the $\mathrm{Si}_{3} \mathrm{~N}_{4} / \mathrm{Si}$ bilayer two bond-and-etch-back technologies are being investigated, both involving a silicon fusion bonding step between $\mathrm{Si}_{3} \mathrm{~N}_{4}$ and $\mathrm{Si}$. The first route involves the use of a high concentration boron layer, which can be used as an etch stop in KOH/IPA (IsoPropyl Alcohol). The second route involves the use of a SOI wafer. By transferring the thin silicon top layer to the nitride wafer it should be possible to obtain the $\mathrm{Si}_{3} \mathrm{~N}_{4} / \mathrm{Si}$ layer. The process schemes are shown in Fig. 2.

In initial bonding experiments it was found that both low stress $\mathrm{Si}_{3} \mathrm{~N}_{4}$ (> $400 \mathrm{~nm}$ thick) as well as high boron doped surfaces (from a
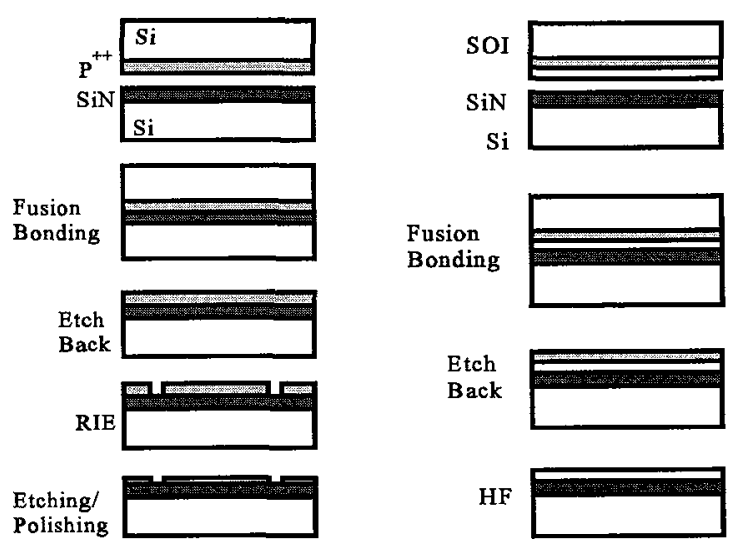

Figure 2: Process schemes for routes 1 (left) and 2 (right) solid source dotation system) are too rough for fusion bonding. In literature successful bonding results between $\mathrm{Si}$ and $\mathrm{Si}_{3} \mathrm{~N}_{4}$ have been mentioned $[5,6]$, but these involved $\mathrm{Si}_{3} \mathrm{~N}_{4}$ layers with a thickness of $300 \mathrm{~nm}$ or less. It was found that by using a 


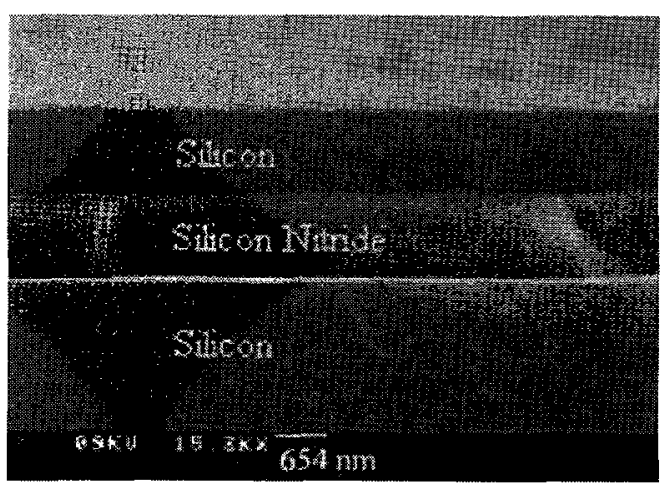

Figure 3: Cross section of $\mathrm{Si}_{-} \mathrm{Si}_{3} \mathrm{~N}_{4}$ layer from the SSD wafer after bond-and-etch-back.

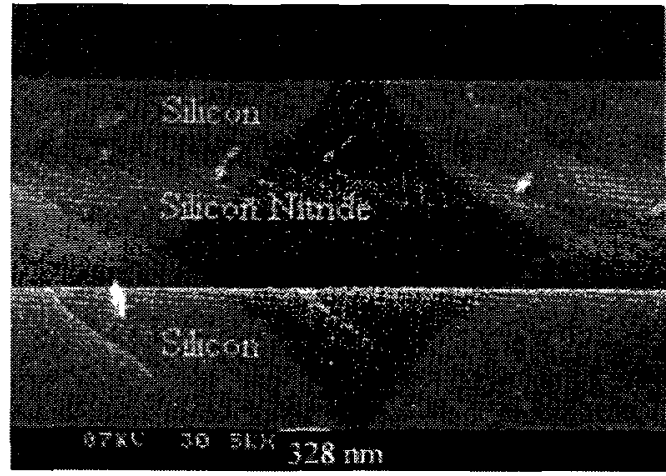

Figure 4: Cross section of Si-Si3N4 layer from the implanted wafer after bond-and-etch-back.

Chemical Mechanical Polishing (CMP) step, previously unbondable $\mathrm{Si}_{3} \mathrm{~N}_{4}$ and boron doped surfaces became bondable [7]. After bonding, the Si wafer is etched back until the etch stop is reached.

\subsection{Experimental}

In recent bond-and-etch-back experiments for route 1,380 $\mu \mathrm{m}$ thick 3" (100) p-type wafers were used. On three wafers a $1.1 \mu \mathrm{m}$ thick low-stress LPCVD $\mathrm{Si}_{3} \mathrm{~N}_{4}$ layer was grown. Boron doping was done with both implantation and solid source dotation (SSD). Implantation was done at $200 \mathrm{keV}$, with a concentration of $2 \cdot 10^{16} \mathrm{~cm}^{-2}$. A $30 \mathrm{~min}$ anneal at $960^{\circ} \mathrm{C}$ resulted in a doping profile with a maximum of about $1 \cdot 10^{20} \mathrm{~cm}^{-3}$ at a depth of $1 \mu \mathrm{m}$. One implanted wafers was polished before further processing, and one wafer was used unpolished. Doping in the SSD system left a surface boron concentration of about $3 \cdot 10^{20} \mathrm{~cm}^{-3}$ and a depth of $2.1 \mu \mathrm{m}$. This wafer was polished before further processing.

Prior to bonding the wafers were given a standard clean, using fuming nitric acid (100\%) and hot nitric acid $\left(70 \%, 90^{\circ} \mathrm{C}\right)$. An IR camera was used to monitor the initial bonding of the wafers. By gently pressing the wafers together in the center with a tweezer, the wafers were brought into close contact.

It was found that the unpolished implanted wafer bonded spontaneously, immediately after getting in close contact. A complete bond was reached within 2 seconds, with only one void. The polished implanted wafer bonded very bad. After continuously pressing, only a few parts remained bonded. The SSD wafer did not bond spontaneaous, but after pressing some more, a complete bond was achieved. After the prebond the wafers were annealed for 2 hours at $900^{\circ} \mathrm{C}$ in $\mathrm{N}_{2}$.

Etching back was carried out in a two-step process. First, a $25 \mathrm{wt} \% \mathrm{KOH}$ solution at $77^{\circ} \mathrm{C}$ was used to etch the bulk silicon until about $40-60 \mu \mathrm{m}$ was left. Then a mixture of $\mathrm{KOH}(23.4 \mathrm{wt} \%)$, IPA (13.3 wt\%) and $\mathrm{H}_{2} \mathrm{O}(63.3 \mathrm{wt} \%)$ at $80^{\circ} \mathrm{C}$ was used to remove the remaining silicon, and stop at the high doped boron layer. During etching, the unbonded parts of the badly bonded waferpair came off, leaving about $10 \%$ of the surface covered with silicon. On the other two wafers about $90 \%$ remained covered with Si. After etching back and stopping at the high concentration boron layer, a thin silicon layer remained on top of the $\mathrm{Si}_{3} \mathrm{~N}_{4}$. The thickness of this layer was $1.1 \mu \mathrm{m}$ in case of the SSD wafer (Fig. 3) and $0.4 \mu \mathrm{m}$ in case of the implanted wafer (Fig. 4).

The bond-and-etch-back procedure still has to be optimized. The main problems are hillock formation during etching in the KOH/IPA system, and small holes which are revealed in the thin Si top layer after etching back. The presence of IPA enhances the hillock formation, since after etching in just KOH no hillocks were visible. Adjusting the concentrations and temperature should strongly reduce the amount and size of the hillocks. The holes are believed to be the result from small air bubbles which are a product from the chemical reaction that takes place at the bonded interface during the annealing step.

These bubbles have not disappeared because of the rather low annealing temperature. At temperatures 
above $1000^{\circ} \mathrm{C}$ these bubbles should disappear, but at this temperature the concentration profile of the implanted wafers will change significantly.

In route 2 the etch stop is provided by the buried oxide (BOX) layer from the SOI wafer. So the thin silicon layer is still unaffected by etching back the bulk of the SOI wafer. Removing the oxide layer with buffered HF finally leaves the thin silicon layer on top of the silicon nitride. The advantage of route 2 is that by using SOI wafers with a Si top layer of several hundred nm only a small amount of Si has to be removed by either polishing or etching to obtain the required thickness. Experiments for route 2 will be carried out in the near future.

\section{PERFORMANCE MODELLING}

\subsection{Thermal response}

Although we aim at a bolometer which is suspended by small $\mathrm{Si}_{3} \mathrm{~N}_{4}$ beams the first examples will be on closed membranes. To estimate the thermal response of such bolometers we have used a simple numerical model describing the heating of the membrane and the corresponding resistance change of the high $-T_{c}$ thermometer. For simplicity and to speed up simulations the actual membrane is approximated by a circular shape. The diameter is chosen such that the detector area is conserved. The resistance of the transition edge thermometer is modelled by series connection of annular rings of high- $\mathrm{T}_{\mathrm{c}}$ film, coaxial on the membrane. The resistance is a linear function of the temperature (for small $\Delta \mathrm{T}$ ). Similar simulations have been described by Fenner et al. [8].

First we modelled the Si-membrane bolometers. They consist of a $1 \mu \mathrm{m}$ Si membrane, a $50 \mathrm{~nm}$

Table 1: Thermal properties of bolometer materials at $90 \mathrm{~K}$ (From $[9,10,11,12]$ ). " $\mathrm{k}$ of $\mathrm{Si}_{3} \mathrm{~N}_{4}$ is calculated from the data in [13].

\begin{tabular}{|lll|}
\hline material & $\kappa(W / \mathrm{cmK})$ & $\mathrm{c}\left(\mathrm{W} / \mathrm{cm}^{3} \mathrm{~K}\right)$ \\
\hline $\mathrm{Si}\left([\mathrm{B}]=3 \cdot 10^{20} \mathrm{~cm}^{-3}\right)$ & 0.5 & 0.52 \\
$\mathrm{Si}_{3} \mathrm{~N}_{4}$ & $0.012^{*}$ & 0.31 \\
$\mathrm{YSZ} / \mathrm{CeO}_{2}$ & 0.015 & 0.7 \\
$\mathrm{GdBa}_{2} \mathrm{Cu}_{3} \mathrm{O}_{7-8}(a b$-plane $)$ & 0.085 & 1.1 \\
\hline
\end{tabular}

$\mathrm{YSZ} / \mathrm{CeO}_{2}$ bufferlayer, a $50 \mathrm{~nm} \mathrm{GdBa} \mathrm{Cu}_{3} \mathrm{O}_{7-8}$ high- $\mathrm{T}_{6}$ film, and a $100 \mathrm{~nm} \mathrm{PtO}_{x}$ passivation layer. For the thermal properties the values listed in Table 1 have been used. Assuming a negligible contribution from the $\mathrm{PtO}_{\mathrm{x}}$ passivation layer, the average thermal conductivity becomes $\mathrm{\kappa}=0.42 \mathrm{~W} / \mathrm{cmK}$ and the average heat capacity $\mathrm{c}=0.57 \mathrm{~J} / \mathrm{cm}^{3} \mathrm{~K}$. Both values are dominated by the properties of the Si membrane. Putting these values into the simulations we found $\mathrm{G}=7 \cdot 10^{-4} \mathrm{~W} / \mathrm{K}$ and $\tau=6 \cdot 10^{-4} \mathrm{~s}$, close to the actually measured values of $\mathrm{G}=4.5 \cdot 10^{-4} \mathrm{~W} / \mathrm{K}$ and $\tau=4 \cdot 10^{-4} \mathrm{~s}[3]$.

In the $\mathrm{Si}_{3} \mathrm{~N}_{4}$ membrane bolometers most of the $\mathrm{Si}$ is replaced by $\mathrm{Si}_{3} \mathrm{~N}_{4}$. By using inhibition structuring [3] the single crystalline silicon top layer of approximately $200 \mathrm{~nm}$ is only present at the location of the high- $T_{c}$ meander. The average $\kappa$ and $c$ in the central part of the membrane with $r<r_{1}$, can be estimated to be $0.08 \mathrm{~W} / \mathrm{cmK}$ and $0.4 \mathrm{~J} / \mathrm{cm}^{3} \mathrm{~K}$, respectively. Outside the region of the meander $\left(r>r_{l}\right) \kappa$ and $\mathrm{c}$ are 0.02 $\mathrm{W} / \mathrm{cmK}$ and $0.4 \mathrm{~J} / \mathrm{cm}^{3} \mathrm{~K}$. The radiation is focused and absorbed homogeneously in the area with $\mathrm{r}<\mathrm{r}_{2}$, and the perimeter of the membrane is $r_{3}$. Fig. 5 shows an example of a calculated temperature profile and the corresponding step response of the resistance. In Table 2 the resulting $G$ and $\tau$ are listed for different $r_{3} / r_{2}$, with $r_{2}=0.55 \mathrm{~mm}$ (detector requirement) and $r_{1}=0.8 r_{2}$. In addition the values of $G^{\prime}$ and $\tau^{\prime}$ are added, which are the corrected values of $G$ and $\tau$ for the heat conductance due to the contact leads.

A further reduction of $\mathrm{G}$ is possible by etching windows in the $\mathrm{Si}_{3} \mathrm{~N}_{4}$ membrane. In the optimum situation the central region of the bolometer $\left(r<r_{2}\right)$ is suspended by small $\mathrm{Si}_{3} \mathrm{~N}_{4}$ beams. This detector can simply be modelled as a heatcapacitance $\mathrm{C}$ equal to the heatcapacitance of central region of the bolometer, connected to the heatsink via a thermal conductance $G$, equal to the heat conductance of the beams 

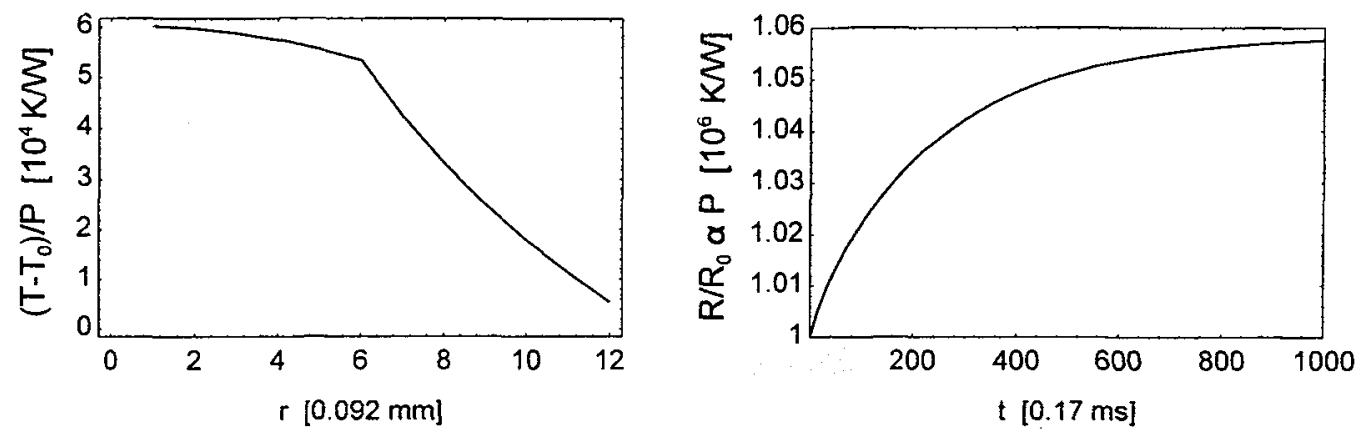

Figure 5: Steady state temperature profile and step response of a ring model bolometer on a $\mathrm{Si}_{3} \mathrm{~N}_{4}$ membrane $\left(\mathrm{r}_{3} / \mathrm{r}_{2}=2, \mathrm{r}_{2}=0.55\right.$ $\mathrm{mm}$ ).

(including the contact leads). In case of 4 beams with each a length $0.5 \mathrm{~mm}$ and width $0.2 \mathrm{~mm}$, the estimated $\mathrm{G}$ equals $8 \cdot 10^{-6} \mathrm{~W} / \mathrm{K}$ (including silicon along contact leads), $\mathrm{C}=6 \cdot 10^{-6} \mathrm{~J} / \mathrm{K}$ (including silver black absorber) and $\tau=0.07 \mathrm{~s}$.

Table 2: $G, \tau$ and NEP of the $\operatorname{SiN}_{x}$ membrane bolometer as determined from the numerical simulations. $G^{\prime}$ and $\tau$ ' are the corrected values of $G$ and $\tau$ due to the heat conductance of the contact leads with a total width of $0.2 \mathrm{~mm}$. $C_{e}$ is the effective heat capacity $G^{\prime} \tau$. "bolometer suspended by 4 legs as described in the text.

\begin{tabular}{|lllllllll|}
\hline $\mathrm{r}_{3} / \mathrm{r}_{2}$ & $\mathrm{G}(\mathrm{W} / \mathrm{K})$ & $\begin{array}{l}\tau \\
(\mathrm{s})\end{array}$ & $\begin{array}{l}\mathrm{G}^{\prime} \\
(\mathrm{W} / \mathrm{K})\end{array}$ & $\begin{array}{l}\tau \\
(\mathrm{s})\end{array}$ & $\begin{array}{l}\mathrm{C}_{\mathrm{e}} \\
(\mathrm{J} / \mathrm{K})\end{array}$ & $\begin{array}{l}\mathrm{NEP}_{\text {phonon }} \\
(\mathrm{W} / \sqrt{\mathrm{Hz}})\end{array}$ & $\begin{array}{l}\mathrm{NEP}_{\text {excess }} \\
(\mathrm{W} / \sqrt{\mathrm{Hz}})\end{array}$ & $\begin{array}{l}\mathrm{NEP}_{\text {total }} \\
(\mathrm{W} / \sqrt{\mathrm{H} z})\end{array}$ \\
\hline 1.5 & $2.5 \cdot 10^{-5}$ & 0.023 & $3.3 \cdot 10^{-5}$ & 0.017 & $6 \cdot 10^{-7}$ & $4.3 \cdot 10^{-12}$ & $2.1 \cdot 10^{-12}$ & $4.8 \cdot 10^{-12}$ \\
2 & $1.7 \cdot 10^{-5}$ & 0.042 & $2.1 \cdot 10^{-5}$ & 0.034 & $7 \cdot 10^{-7}$ & $3.4 \cdot 10^{-12}$ & $1.9 \cdot 10^{-12}$ & $3.9 \cdot 10^{-12}$ \\
3 & $1.2 \cdot 10^{-5}$ & 0.010 & $1.4 \cdot 10^{-5}$ & 0.085 & $1.2 \cdot 10^{-6}$ & $2.8 \cdot 10^{-12}$ & $2.0 \cdot 10^{-12}$ & $3.4 \cdot 10^{-12}$ \\
\hline $2^{*}$ & & & $8 \cdot 10^{-6}$ & 0.07 & $6 \cdot 10^{-7}$ & $2.1 \cdot 10^{-12}$ & $1.0 \cdot 10^{-12}$ & $2.3 \cdot 10^{-12}$ \\
\hline
\end{tabular}

\subsection{Absorption efficiency}

The measured absorption efficiency $\eta$ of the silicon membrane bolometer in the infrared is only 0.13 at $\lambda=13 \mu \mathrm{m}$ and 0.16 at $\lambda=6 \mu \mathrm{m}$ [3]. At $85 \mu \mathrm{m}$ an absorptance around $10 \%$ has been predicted [14]. Although less important if the bolometer is mounted in an optical cavity, an absorption layer is required for good performance. Among the most promising absorption layers for use in the far infrared are metal blacks. An absorptance $\eta$ of 0.8 at $\lambda=85 \mu \mathrm{m}$ was measured for a $6.2 \mu \mathrm{m}$ Ag-vacuum mixture with a filling percentage of $1 \%$ [15]. The additional heat capacitance of such a layer deposited on the receiving area of the bolometer is about $1 \cdot 10^{-7} \mathrm{~J} / \mathrm{K}$. This corresponds with a relative increase of the effective heatcapacity and the bolometer time constant (Table 2) of only 9 to $16 \%$.

\subsection{Noise calculations}

A calculation of the detector NEP of the $\mathrm{Si}_{3} \mathrm{~N}_{4}$ membrane bolometer (with typical parameters $\mathrm{T}_{\mathrm{c}}=80 \mathrm{~K}$, $\mathrm{R}=5 \mathrm{k} \Omega, \alpha=1 \mathrm{~K}^{-1}[3]$, and $\mathrm{G}$ and $\tau$ as listed in Table 2) shows that the most fundamental and important contributions to the detector noise are the phonon noise (i.e. the noise related to the thermal conductance $\mathrm{G})$, and the excess noise in the high- $\mathrm{T}_{\mathrm{c}}$ film. Thermal fluctuation noise and amplifier noise can be reduced sufficiently by using a suitable biasing scheme, e.g. a bridge configuration with ac bias current and a low noise amplifier. The Johnson noise and the background radiation noise are negligible. In Table 2 the phonon NEP $=\sqrt{ }\left(4 \mathrm{kT} T^{2} \mathrm{G}^{1} / \eta^{2}\right)$ is listed for $T=80 \mathrm{~K}$ and $\eta=0.8$.

The excess noise of the superconducting thermometer depends strongly on the structural quality of the high- $T_{c}$ material. Analysis of various noise measurements showed us that at the midpoint of the superconducting transition the excess noise of epitaxial $\mathrm{YBa}_{2} \mathrm{Cu}_{3} \mathrm{O}_{7.8}$ can be estimated from the Hooge 
law $S_{v}(f) / V^{2}=\gamma /\left(n_{c} E f\right)$, with $S_{v}^{1 / 2}(f)$ the voltage noise spectral density, $V$ the voltage, $\gamma$ a dimensionless constant, $n_{c}$ the charge carrier density and $f$ the frequency [4]. An average value $\gamma / n_{c}=5 \cdot 10^{-22} \mathrm{~cm}^{3}$ was found. The volume $E$ of the meandered high- $T_{c}$ film is approximately $2 \cdot 10^{-8} \mathrm{~cm}^{3}$. The NEP can be calculated by substituting the Hooge law into $\mathrm{NEP}_{\text {excess }}=\mathrm{S}_{\mathrm{v}}{ }^{1 / 2} /|\mathrm{S}|$, with $|\mathrm{S}|=\eta \mathrm{IR} \boldsymbol{\alpha} / \mathrm{G}_{\mathrm{e}}|1+\mathrm{i} 2 \pi \mathrm{f} \tau|$ the bolometer responsivity. $G_{e}$ is the effective thermal conductance with the thermal feedback due to the bias current heating taken into account and $\tau_{e}$ is the corresponding effective time constant. Typically, $\mathrm{G}_{\mathrm{e}}$ is 0.7 times the heat conductance $G$. Minimizing the NEP with respect to signal modulation frequency $f$ yields an

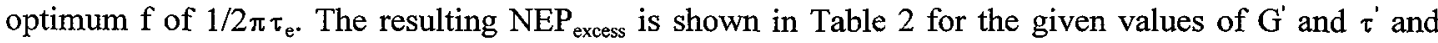
$\eta=0.8$.

The last column shows the total NEP due to both phonon and excess noise. The required NEP is realized for the last three options, with the lowest NEP for a structured membrane.

\section{CONCLUSIONS}

It is expected that with a combination of $\mathrm{Si}_{3} \mathrm{~N}_{4} / \mathrm{Si}$ membrane fabrication and existing technologies as presented in [3] high- $T_{c}$ bolometers can be made with the required specifications. The proposed routes for the production of the $\mathrm{Si}_{3} \mathrm{~N}_{4} / \mathrm{Si}$ layers and membranes are still under investigation. The main points of attention at this moment are to increase the bonding yield, and achieve an etched-back surface without hillocks. The combination of micromachining and superconductive films provides an interesting challenge, leading to new possibilities for the development of far infrared detectors with unequalled performance at temperatures around $80 \mathrm{~K}$.

\section{Acknowledgments}

The authors would like to thank C. Gui for carrying out the CMP experiments. This project funded by the European Space Agency under contract no. 11738/95/NL/PB (project manager Dr. E. Armandillo).

\section{References}

[1] Wijnbergen J.J., de Korte P.A.J., de Nivelle M.J.M.E. , Proc. SPIE 2578 (1995) 306.

[2] Richards P.L. et al., Appl. Phys. Lett. 54 (1989) 283-285.

[3] Neff H., Laukemper J., Khrebtov I.A., Tkachenko A.D., Steinbeiss E., Michalke W., Burnus M., Heidenblut T., Hefle G. and Schwierzi B., Appl. Phys. Lett. 66 (1995) 2421-2423.

[4] de Korte P.A.J., de Nivelle M.J.M.E., Wijnbergen J.J., Proc. SPIE 2578 (1995) 294.

[5] Bower R.W., Ismail M.S., Roberts B.E., Appl. Phys. Lett. 62 (1993) 3485.

[6] Harendt C., Graf H.-G., Höfflinger B., Penteker E., J. Micromech. Microeng. 2 (1992) 113.

[7] Gui C., Gardeniers J.G.E., Elwenspoek M., Albers H., Lambeck P.V., "Silicon fusion bonding with chemical mechanical polishing", Sensor Conf., Delft (The Netherlands) 20-21 March, 1996.

[8] Fenner D.B., Li Q., Hamblen W.D., Luo J, and Hamblen D.G., Proc. SPIE 2159 (1994) 10-20.

[9] Touloukian Y.S., Thermophysical properties of Matter Vol. 2 and 5 (Plenum, New York, 1970).

[10] Verghese $S$., Infrared detection with high- $\mathrm{T}_{\mathrm{c}}$ bolometers and response of $\mathrm{Nb}$ tunnel junctions to picosecond voltage pulses ( $\mathrm{PhD}$ thesis, University of California at Berkeley, 1993).

[11] Inderhees S.E. et al., Phys. Rev. Lett. 66 (1991) 232-235.

[12] Hagen S.J., Wang Z.Z. and Ong N.P., Phys. Rev. B 40 (1989) 9389-9392.

[13] Johnson B.R., Foote M.C., Marsh H.A. and Hunt D.B., Proc. SPIE 2267 (1994).

[14] Zhang Z.M. and Flik M.I., IEEE Trans. Appl. Superc. 3 (1993) 1604-1607.

[15] Neff H. , Henkel S., Sass J.K. , Steinbeiss E., Ratz P., Müller J. and Michalke W., "Optical properties of ultrarough silver films on silicon", submitted to J. Appl. Phys. 